\title{
Efficient Isolation and Characterization of a Cellulase Hyperproducing Mutant Strain of Trichoderma reese $i^{\text {s }}$
}

\author{
Zongsheng Zou ${ }^{1,2}$, Yunying Zhao ${ }^{1,2}$, Tingzhou Zhang ${ }^{3}$, Jiaxing $\mathrm{Xu}^{4}$, Aiyong $\mathrm{He}^{4}$, and $\mathrm{Yu} \mathrm{Deng}^{1,2 *}$ \\ ${ }^{1}$ National Engineering Laboratory for Cereal Fermentation Technology (NELCF), Jiangnan University, 1800 Lihu Road, Wuxi, Jiangsu \\ 214122, P.R. China \\ ${ }^{2}$ School of Biotechnology, Jiangnan University, 1800 Lihu Road, Wuxi, Jiangsu 214122, P.R. China \\ ${ }^{3}$ Zhejiang Cofine Biotech. Inc., No. 1 Chungchao Road, Hightec., District of Haining, Zhejiang 314400, P.R. China \\ ${ }^{4}$ Jiangsu Key Laboratory for Biomass-Based Energy and Enzyme Technology, Huaiyin Normal University, Huaian 223300, P.R. China
}

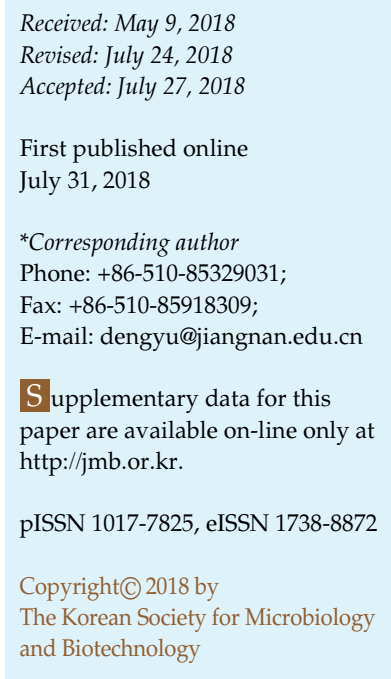

A cellulase hyperproducing mutant strain, JNDY-13, was obtained using the ARTP mutation system and with Trichoderma reesei RUT-C30 as the parent strain. Whole-genome sequencing of JNDY-13 confirmed that 105 of the 653 SNPs were point mutations, 336 mutations were deletions and 165 were insertions. Moreover, 99 mutations were insertions and duplications. Among all the mutations, the one that occurred in the galactokinase gene might be related to the production of cellulases in T. reesei JNDY-13. Moreover, the up-regulation of cellulase and hemicellulase genes in JNDY-13 might contribute to higher cellulases production. Under optimal conditions, the highest cellulase activity by batch fermentation reached $4.35 \mathrm{U} / \mathrm{ml}$, and the highest activity of fed-batch fermentation achieved was $5.40 \mathrm{U} / \mathrm{ml}$.

Keywords: Cellulase, Trichoderma reesei, ARTP-LiCl, NGS, galactokinase

\section{Introduction}

Cellulose and hemicellulose polysaccharides are $\beta-(1,4)$ linked glucose polymers with diverse compositions. They make up $60-80 \%$ of the plant cell wall, and they are derived from photosynthesis and the absorption of carbon dioxide by plants [1]. Therefore, the conversion of cellulosic and hemicellulosic polymers into bioethanol or platform chemicals is considered important for the attempt to reduce carbon dioxide emissions and alleviate the overdependence on fossil fuels [2]. Cellulases produced by certain filamentous fungi, such as Trichoderma reesei, are considered the most optimal enzyme compound to thoroughly decompose cellulose into glucose. Glucose, in turn, can be utilized to synthesize other valuable chemicals and energy. Cellulases have extensive applications in animal feed, textiles, grain alcohol fermentation, pulp and paper processing, starch processing, and the pharmaceutical, malting, and food industries [3-5].

Sixteen hemicellulolytic and ten cellulolytic enzymeencoding genes were identified in $T$. reesei through a genome-wide analysis [6]. T. reesei Rut-C30 is the most extensively studied strain $[7,8]$. It evolved from the wildtype strain $T$. reesei QM6a through three rounds of mutagenesis (N-nitroguanidine mutagenesis and ultraviolet (UV) light mutagenesis), which was followed by a screening for the release from carbon catabolite repression (CCR) and high production of cellulases [9-11]. Furthermore, genetic and phenotypic changes in $T$. reesei Rut-C30 have been extensively studied [8, 12]. Consequently, many details about the catalytic function and molecular structure of these cellulases and hemicellulases have already been illuminated, and several aspects of the regulatory mechanism of their secretion have also been elucidated.

The ARTP (atmospheric and room temperature plasmas) mutation system is a novel mutagenesis technology, and it 
has been widely applied in mutation breeding of microorganisms (e.g., fungi, actinomycetes, and bacteria). This enhances the production of industrial products as a consequence of its superior characteristics, which include operational safety, lower costs, and low plasma temperature $[13,14]$. The plasma can be easily generated, and it can destroy a DNA strand instantaneously, both at room temperature and atmospheric pressure. As a result, various kinds of breakages of oligonucleotides and plasmid DNA are generated with different plasma dosage [15-19].

In this study, ARTP was employed to gain a mutant T. reesei strain with high cellulase activity. The mutant strain was analyzed by next-generation sequencing, and transcription levels of key genes closely related to cellulases and hemicellulases were characterized by Reverse Transcriptionquantitative PCR. Finally, the fermentation medium and process were optimized to achieve high cellulase activity.

\section{Materials and Methods}

\section{Strain and Culture Conditions}

T. reesei RUT-C 30 was used as the parental strain, and it was grown in $250 \mathrm{ml}$ shake flask at $30^{\circ} \mathrm{C}$ on a rotary shaker $(200 \mathrm{rpm})$. The seed medium was prepared with $20 \mathrm{~g} / 1$ lactose [20]. Composition of the fermentation medium was as follows $(1 \mathrm{~L})$ : $10 \mathrm{~g}$ lactose, $10 \mathrm{~g}$ avicel, $12 \mathrm{~g}$ corn steep liquor, $1.5 \mathrm{~g}\left(\mathrm{NH}_{4}\right)_{2} \mathrm{SO}_{4}, 1 \mathrm{~g} \mathrm{MgSO}_{4}, 1 \mathrm{~g}$ $\mathrm{CaCl}_{2}, 2 \mathrm{ml}$ Tween 80, and $1 \mathrm{ml}$ Mandels solution [21]. The inoculum was prepared by transferring $T$. reesei RUT-C30 spores into a $500 \mathrm{ml}$ shake flask containing $300 \mathrm{ml}$ of seed medium. The seeds were grown in a shake flask at $30^{\circ} \mathrm{C}$ at $200 \mathrm{rpm}$ for 3 days, and then transferred to a bioreactor (5-L bioreactor, Bailun Shanghai). The fermentations were carried out at $30^{\circ} \mathrm{C}$ with aeration of $1 \mathrm{vvm}$ and a stirring speed of $400 \mathrm{rpm}$. The $\mathrm{pH}$ was maintained at 5.0 by supplementing $2 \mathrm{M} \mathrm{NaOH}$ or $2 \mathrm{M} \mathrm{H}_{2} \mathrm{SO}_{4}$. When performing fed-batch fermentation, the concentrated lactose $(125 \mathrm{~g} / \mathrm{l})$ and $\left(\mathrm{NH}_{4}\right)_{2} \mathrm{SO}_{4}(27.5 \mathrm{~g} / \mathrm{l})$ were fed into the bioreactor during the fermentation. The biosamples were taken regularly and treated through a suction filter. The filtrate was collected for subsequent analysis.

\section{Screening of Hyperproducing Mutants by ARTP}

The ARTP mutation system was manufactured by Tsinghua University [19]. The working radio frequency (RF) power input was $100 \mathrm{~W}$, and the gas flow volume was 10.0 SLM (standard liter per minute). Ten $\mu \mathrm{l}$ of fresh spore (spore concentration: $10^{7-8} / \mathrm{ml}$ ) was dispersed onto a sterilized plate (12 $\mathrm{mm}$ in diameter), and then the plate was put into a vessel with a fixed treatment distance of $2.0 \mathrm{~mm}$. The treatment time varied from 40 to $260 \mathrm{sec}$. To resuspend the spores, the plate was immediately transferred to sterile saline and shaken for $30 \mathrm{sec}$ after mutation treatment. With appropriate dilution, $200 \mu \mathrm{l}$ of spore suspension was well-distributed onto selective agar plates that contained $10 \mathrm{~g} / 1$ carboxymethyl cellulose sodium (CMC), $3 \mathrm{~g} / 1$ lactose, and $1 \mathrm{~g} / 1$ lithium chloride. Afterwards, the plates were cultured in the mold incubator for 4 days at $30^{\circ} \mathrm{C}$. Then, the plates were dyed with Congo red for $30 \mathrm{~min}$ and washed with sterile $\mathrm{NaCl}$ solution. Colonies that were surrounded with large halos on the plates were chosen as the original strains for the next mutagenesis cycle [22]. The H/C number was defined as the diameter of the halo produced by hydrolysis divided by the diameter of the colony. Since the wild type $\mathrm{H} / \mathrm{C}$ varies from 1.02 to 1.26 , an $\mathrm{H} / \mathrm{C}>1.3$ indicates that the mutagenesis was positive and an $\mathrm{H} / \mathrm{C}<1$ indicates that the mutagenesis was negative.

\section{Measurement of Cellulose Content, Fungal Biomass, and Lactose Consumption}

To determine the cellulose content of the cultures, $10 \mathrm{ml}$ of sample was centrifuged $(3,000 \mathrm{~g}, 20 \mathrm{~min})$. Then, the pellets were resuspended in $3 \mathrm{ml}$ of acetic acid-nitric acid solution (made of $15 \mathrm{ml}$ of nitric acid with $150 \mathrm{ml}$ of $80 \%$ acetic acid). Next, they were incubated in a water bath for $30 \mathrm{~min}$ before being cooled down and centrifuged (3,000 g, $20 \mathrm{~min})$. Afterwards, the pellets were washed with an equal amount of distilled water. The remaining solid was primarily cellulose, and it was dried to constant weight at $40^{\circ} \mathrm{C}$ under reduced pressure [23]. The measured value of the residual cellulose content was an average of three replicates. The fungal biomass concentration was measured by filtration [24]. The biomass was washed with an appropriate amount of water and dried on filter paper at $105^{\circ} \mathrm{C}$ to a constant weight. The dry biomass weight was calculated as the difference between the total dry weight (containing cellulose and mycelium) and the residual cellulose weight.

The residual lactose was measured by HPLC (higher performance liquid chromatography) (Bio-Rad HPX-87P ion exclusion column) [25]. Samples used for analysis were stored at $-20^{\circ} \mathrm{C}$ before analysis.

\section{Cellulase and Galactokinase Assays}

Filter Paper Unit (FPU) was chosen to measure the cellulase activity, according to the IUPAC protocol [26]. For galactokinase activity analysis, an HPLC-based method was applied to measure the concentration of galactose-1-phosphate in $1 \mathrm{ml}$ of the reaction solution, which contained $10 \mathrm{mM}$ ATP, $20 \mathrm{mM}$ D-galactose, $0.7 \mathrm{ml}$ crude extract, and $10 \mathrm{mM} \mathrm{MgSO}_{4}$ (in $0.1 \mathrm{M}$ phosphate buffer, $\mathrm{pH}$ 7.6). Specifically, $0.2 \mathrm{~g}$ of fresh wet mycelia was added into $2 \mathrm{ml}$ of $0.1 \mathrm{M}$ phosphate buffer, and the crude extract was obtained after ultrasonic homogenization in an ice bath. The enzymatic reaction was initiated by the addition of D-galactose, and it was incubated at $37^{\circ} \mathrm{C}$ for $30 \mathrm{~min}$. Then, the mixture was put on ice to terminate the reaction. To remove the $\mathrm{SO}_{4}^{2-}$, it was precipitated by adding an equal molar amount of $\mathrm{Ba}(\mathrm{OH})_{2}$. Then, the mixture was centrifuged at $8,500 \mathrm{~g}$ for $5 \mathrm{~min}$. The content of galactose-1phosphate in the supernatant was assayed by HPLC with an $\mathrm{H}^{+}$ exchange column (Merck Polyspher OA KC, Germany), using 
$25 \mathrm{mM} \mathrm{H}_{2} \mathrm{SO}_{4}$ as the mobile phase with isocratic elution and a refractive index detector. The column temperature was $30^{\circ} \mathrm{C}$. The amount of galactose-1-phosphate produced was detected at $410 \mathrm{~nm}$. Within the time and conditions of the assay, the formation of galactose-1-phosphate was linear with respect to time [27]. Galactokinase activity was defined as: $1 \mathrm{U}$ is equivalent to $1 \mathrm{mM}$ o-nitrophenol produced per min [28].

\section{RT-qPCR Analysis}

For RNA extraction, an appropriate amount of mycelia was collected by suction filtration after being cultured for 24,60 , or $96 \mathrm{~h}$. Then it was ground in liquid nitrogen. A certain amount of Trizol reagent (Sangon, Shanghai, China) was added, and total RNA was isolated. Synthesis of cDNA from the total extracted RNA was conducted using the HiFiScript gDNA Removal cDNA Synthesis Kit (CWBiotech, China), according to the manufacturer's instructions. The RT-qPCR reaction was carried out in triplicate in a CFX96 Touch Real-time PCR Detection system (BioRad, USA). The PCR reaction was set up according to the manufacturer's instructions. The relative gene expression was determined by the $2^{-\Delta \Delta C t}$ method, using sar1 expression as the reference gene for normalization [29]. The primers for gene amplification are listed in Table S1.

\section{Whole-Genome Sequencing Analysis and Transcriptional Analysis}

Whole-genome shotgun sequencing of the hyperproducing mutant was conducted on the Illumina Genome Analyzer (HiSeq 2500) by Sangon Biotech, Shanghai, China. The general process was previously described by Ivanova et al. [30]. Two independent samples were analyzed, and the genome sequences were uploaded to SRA with access numbers: SRP124905.

\section{Results}

\section{Screening of Hyperproducing Mutants from T. reesei RUT-C30}

Since the whole-genome sequencing of $T$. reesei was completed in 2008, there have been more than 20 genes that have been identified as being directly associated with the secretion of cellulases [6]. Although many genetic engineering methods have already been successfully implemented in the study of T. reesei, the progress is still slow. In this study, ARTP-LiCl compound mutagenesis was applied to acquire mutants with high cellulase activity. As the lethality rate of the ARTP mutation system was dose-dependent, the relationship between various plasma treatment times and the lethality rate of $T$. reesei RUT-C30 was investigated (Fig. 1). The lethality rate was calculated by a previously reported method [31]. As shown in Fig. 1A, the treatment times with successful mutagenesis were 80, 140, 200, 220, 240 , and $260 \mathrm{sec}$. The treatment time of $240 \mathrm{sec}$ was selected to obtain hyperproducing mutants from $T$. reesei RUT-C30 because this was the time point at which mutants with higher cellulase activity were found. Congo red can form a red complex with certain polysaccharides, such as cellulose, CMC, and hemicellulose, but it cannot react with cellobiose, glucose, or polysaccharide hydrolyzate. Therefore, the Congo red method produces unstained circular zones around the colonies, and it strongly contrasts with the red background of undigested substrate after treatment with $\mathrm{NaCl}$ solution [22]. In this study, the screening strategy was based on the size of the hydrolysis halos produced by colonies. The selected mutants were cultured in fermentation medium to determine the FPU activity. The mutant colony with the highest FPU was selected for the next round of mutagenesis. After 5 rounds of mutagenesis, the hyperproducing mutant T. reesei JNDY-13 was obtained.
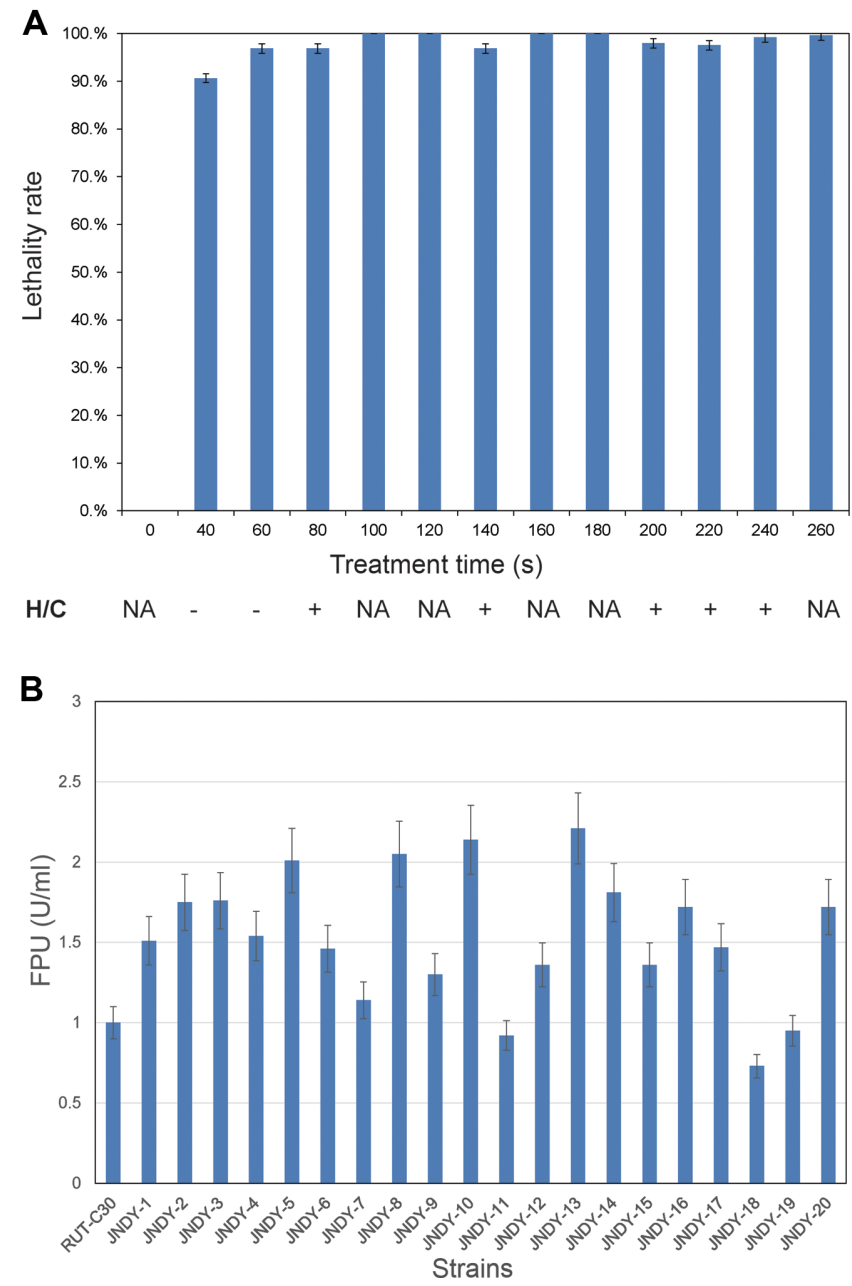

Fig. 1. T. reesei mutants created by the ARTP mutation system. (A) Lethality rate and (B) FPU activity of mutants. 


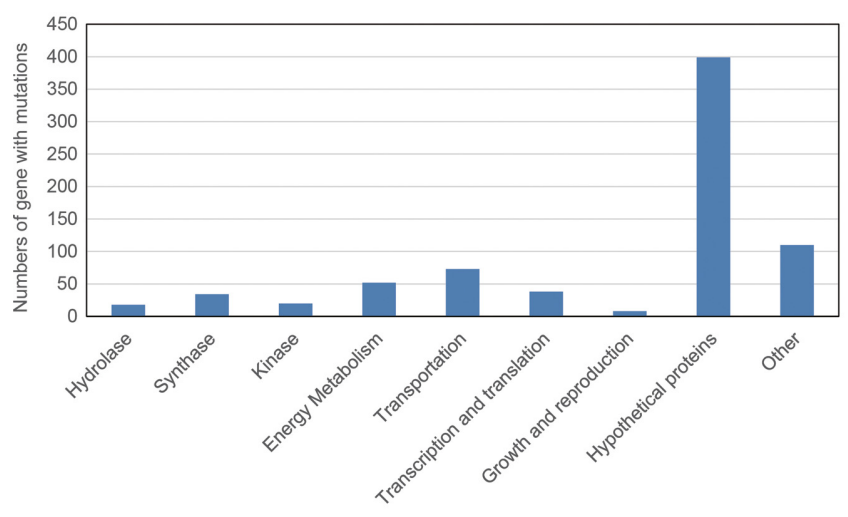

Fig. 2. Categories of the mutant genes of T. reesei JNDY-13.

(Fig. 1B). The filter paper activity of $T$. reesei JNDY-13 was $2.21 \mathrm{FPU} / \mathrm{ml}$, which was 2.21 times higher than that of T. reesei RUT-C30.

\section{Whole-Genome Sequencing of JNDY-13}

High-throughput genome sequencing of the hyperproducing mutant JNDY-13 was executed by the Illumina Genome Analyzer (HiSeq 2500) to study genetic changes. Sequence reads generated by the Illumina system were aligned to a reference genome of T. reesei Rut-C30 [6], using the MOM algorithm [32]. For JNDY-13, there were 27,934,787 (94.69\% of total) single-end reads that were mapped by Illumina sequencing. All of the sequencing data generated were analyzed for point mutations (SNPs) and other mutational events [12]. There were 752 mutations (Table S2) that were identified in JNDY-13. Among these, 18 were hydrolases, 34 were synthases, 20 were kinases, 52 were related to energy metabolism, 73 were related to transportation, 38 were related to transcription and translation, 8 were related to growth, 399 were hypothetical proteins, and 110 were related to other functions (Fig. 2). Also, 105 out of the 653 SNPs were confirmed to be point mutations, 336 mutations were deletions, and 165 were insertions. Moreover, 99 mutations were insertions and duplications. There was one important mutation that occurred in the galactokinase gene. The "G" at 2015901 of the galactokinase gene was replaced by "'GGGTTAAAAAGCGACTCAC". Galactokinase has been found to be directly related to the cellulase activity of T. reesei [33]. Gal1-deleted strains down-regulate the induction of cellulase gene expression caused by lactose. Thus, galactokinase could have a significant effect on cellulase production in $T$. reesei. Therefore, an enzymatic assay of this protein was performed. As shown in Fig. 3, the activity of galactokinase in the hyperproducing mutant

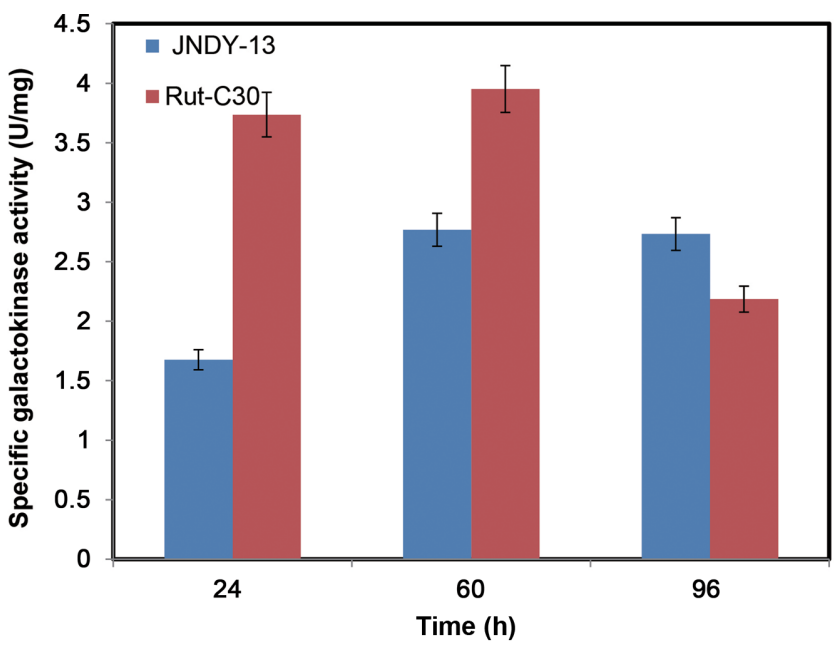

Fig. 3. The specific galactokinase activity of T. reesei Rut-C30 and T. reesei JNDY-13.

was lower than in the parent strain (T. reesei Rut-C30) at 24 and $60 \mathrm{~h}$, but it was slightly higher at $96 \mathrm{~h}$.

\section{Transcriptional Analysis of Key Genes Associated with the Secretion of Cellulases}

In T. reesei, there were five endoglucanases (Cel7B, Cel5A, Cel12A, Cel61A, and Cel45A), two exo-acting cellobiohydrolases (Cel7A and Cel6A), and two characterized $\beta$-glucosidases (Cel1A and Cel3A) that contributed to the total cellulase activity [34, 35]. Moreover, the $T$. reesei genome also contained sixteen hemicellulases, including four GH 95, one GH 10, one GH 74, four GH 11, one GH 67, one GH 62, two GH 54, and two GH 43 [35]. Cell samples were

Table 1. RT-qPCR results of JNDY-13 compared to RutC-30.

\begin{tabular}{lcccl} 
Genes & $24 \mathrm{~h}$ & $60 \mathrm{~h}$ & $96 \mathrm{~h}$ & \multicolumn{1}{c}{ Protein } \\
\hline cel12A & 5.553 & 0.036 & 0.134 & Endoglucanase \\
cel3C & 14.689 & 19.382 & 0.026 & $\beta$-Glucosidase \\
cel3A & 3.775 & 1.062 & 0.166 & $\beta$-Glucosidase \\
cel61A & 0.628 & 3.638 & 0.162 & Endoglucanase \\
cel5A & 0.666 & 1.982 & 0.309 & Endoglucanase \\
cel7A & 2.996 & 0.984 & 0.025 & Cellobiohydrolases \\
cel6A & 0.185 & 0.0002 & 0.714 & Cellobiohydrolases \\
cel3B & 15.834 & 3.0244 & 0.122 & $\beta$-Glucosidase \\
cel7B & 0.426 & 44.838 & 0.189 & Endoglucanase \\
xyn1 & 28.707 & 1.145 & 0.019 & Xylanase \\
xyn2 & 0.006 & 1.573 & 0.298 & Xylanase \\
gal1 & 0.155 & 24.391 & 1.401 & Galactokinase \\
\hline
\end{tabular}

The unit of numbers is fold. 
harvested at 24, 60, and $96 \mathrm{~h}$, and they underwent RT-qPCR analysis (Table 1). The transcription of the gal1 gene was significantly increased at $60 \mathrm{~h}$, when compared to Rut-C30 (24.391). Additionally, 8 of the 11 cellulase and hemicellulase genes of JNDY-13 were up-regulated at $60 \mathrm{~h}$. Thus, the increased transcription of the mutant gal1 gene could be related to the transcription of the cellulase genes. The upregulation of the cellulase genes might be the reason why JNDY-13 had considerably higher cellulase activity compared to Rut-C30.

\section{Fermentation Optimization}

The key factors affecting cellulase production include carbon and nitrogen sources, fermentation temperature, $\mathrm{pH}$, and dissolved oxygen levels in the fermentation medium. As a consequence of the complexity of the process in which cellulases act as both the product and the catalyst for the decomposition of cellulose, the appropriate regulation of the fermentation conditions, such as $\mathrm{pH}$ and temperature, is important for the optimal performance of the production process [36].

The medium optimization experiments were designed based on the Taguchi orthogonal method [37, 38]. According to the results, the optimal composition of the fermentation medium for JNYD-13 was determined to be as follows: $10 \mathrm{~g}$ lactose, $10 \mathrm{~g}$ avicel, $12 \mathrm{~g}$ corn steep liquor, $1.5 \mathrm{~g}\left(\mathrm{NH}_{4}\right)_{2} \mathrm{SO}_{4}$,

Table 2. Intuitive analysis.

\begin{tabular}{|c|c|c|c|c|c|c|c|}
\hline Factor & Lactose & Avicel & Corn steep liquor & $\left(\mathrm{NH}_{4}\right)_{2} \mathrm{SO}_{4}$ & $\mathrm{CaCl}_{2}$ & $\mathrm{MgSO}_{4}$ & $\mathrm{FPU}(\mathrm{IU} / \mathrm{ml})$ \\
\hline Group 1 & 1 & 1 & 1 & 1 & 1 & 1 & 1.70 \\
\hline Group 2 & 1 & 2 & 2 & 2 & 2 & 2 & 2.02 \\
\hline Group 4 & 1 & 4 & 4 & 4 & 4 & 4 & 2.12 \\
\hline Group 5 & 1 & 5 & 5 & 5 & 5 & 5 & 1.60 \\
\hline Group 6 & 2 & 1 & 2 & 3 & 4 & 5 & 1.76 \\
\hline Group 7 & 2 & 2 & 3 & 4 & 5 & 1 & 1.81 \\
\hline Group 8 & 2 & 3 & 4 & 5 & 1 & 2 & 1.66 \\
\hline Group 9 & 2 & 4 & 5 & 1 & 2 & 3 & 1.39 \\
\hline Group 10 & 2 & 5 & 1 & 2 & 3 & 4 & 1.12 \\
\hline Group 11 & 3 & 1 & 3 & 5 & 2 & 4 & 1.60 \\
\hline Group 12 & 3 & 2 & 4 & 1 & 3 & 5 & 1.76 \\
\hline Group 13 & 3 & 3 & 5 & 2 & 4 & 1 & 1.82 \\
\hline Group 14 & 3 & 4 & 1 & 3 & 5 & 2 & 1.61 \\
\hline Group 15 & 3 & 5 & 2 & 4 & 1 & 3 & 1.62 \\
\hline Group 16 & 4 & 1 & 4 & 2 & 5 & 3 & 1.82 \\
\hline Group 17 & 4 & 2 & 5 & 3 & 1 & 4 & 1.93 \\
\hline Group 18 & 4 & 3 & 1 & 4 & 2 & 5 & 0.25 \\
\hline Group 19 & 4 & 4 & 2 & 5 & 3 & 1 & 0.40 \\
\hline Group 20 & 4 & 5 & 3 & 1 & 4 & 3 & 2.01 \\
\hline Group 21 & 5 & 1 & 5 & 4 & 3 & 2 & 0.95 \\
\hline Group 22 & 5 & 2 & 1 & 5 & 4 & 3 & 0.22 \\
\hline Group 23 & 5 & 3 & 2 & 1 & 5 & 4 & 2.06 \\
\hline Group 24 & 5 & 4 & 3 & 2 & 1 & 5 & 1.89 \\
\hline Mean 2 & 1.547 & 1.546 & 1.570 & 1.734 & 1.395 & 1.560 & \\
\hline Mean 3 & 1.684 & 1.626 & 1.931 & 1.872 & 1.316 & 1.567 & \\
\hline Mean 4 & 1.282 & 1.484 & 1.815 & 1.348 & 1.583 & 1.766 & \\
\hline Mean 5 & 1.366 & 1.611 & 1.539 & 1.096 & 1.780 & 1.452 & \\
\hline Range & 0.675 & 0.142 & 0.952 & 0.776 & 0.464 & 0.314 & \\
\hline
\end{tabular}

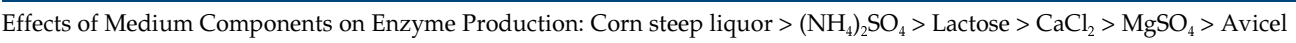


Table 3. Orthogonal experiment to find the optimal parameters for cellulase fermentation.

\begin{tabular}{lcccc}
\hline & $\begin{array}{c}\text { Temperature } \\
\left({ }^{\circ} \mathrm{C}\right)\end{array}$ & $\begin{array}{c}\text { Agitation } \\
(\mathrm{rpm})\end{array}$ & $\begin{array}{c}\text { Aeration } \\
(\mathrm{vvm})\end{array}$ & $\begin{array}{c}\text { FPU } \\
(\mathrm{U} / \mathrm{ml})\end{array}$ \\
\hline Group 1 & 28 & 400 & 1 & 4.74 \\
Group 2 & 28 & 600 & 2 & 4.26 \\
Group 3 & 30 & 400 & 2 & 1.22 \\
Group 4 & 30 & 600 & 1 & 5.63 \\
\hline
\end{tabular}

$1 \mathrm{~g} \mathrm{MgSO}_{4}, 1 \mathrm{~g} \mathrm{CaCl}_{2}, 2 \mathrm{ml}$ Tween 80, and $1 \mathrm{ml}$ Mandels solution per liter medium (Table 2 ).

The best temperature, aeration, and agitation rates were investigated by the orthogonal method [37, 38]. The temperature was set at $28^{\circ} \mathrm{C}$ or $30^{\circ} \mathrm{C}$. The agitation rate was set at 400 or $600 \mathrm{rpm}$, and aeration rate was set at 1 or $2 \mathrm{vvm}$ in the 5-L bioreactor. As shown in Table 3, the orthogonal analysis results indicate that the order of importance of the parameters affecting cellulase production was: agitation $>$ aeration $>$ temperature. The optimal conditions for cellulase production were: $28^{\circ} \mathrm{C}, 2 \mathrm{vvm}$, and $400 \mathrm{rpm}$. The result of the batch fermentation under optimal conditions is shown in Fig. 4 . The highest cellulase activity was $4.35 \mathrm{U} / \mathrm{ml}$ at $96 \mathrm{~h}$, which was almost twice that of what was observed in the shake flask.

\section{Fed-Batch Fermentation}

Consistent with most results, the most suitable temperature for cellulase production was $28^{\circ} \mathrm{C}$, and a temperature of $30^{\circ} \mathrm{C}$ contributed to their growth. In this study, the growth was noticeably lagged when $28^{\circ} \mathrm{C}$ was chosen, and it took much longer to accumulate a certain amount of biomass. Since cellulase production is closely related to the

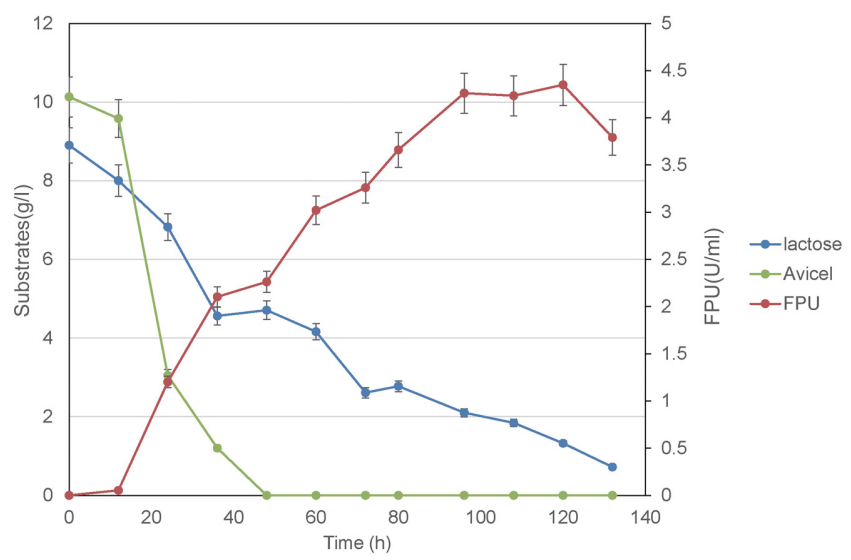

Fig. 4. Cellulase production of T. reesei JNDY-13 by batch fermentation. accumulation of biomass, $30^{\circ} \mathrm{C}$ was chosen for a high yield of cellulases. Agitation was set at $400 \mathrm{rpm}$, and aeration was set at $1 \mathrm{vvm}$ during the batch fermentation [39]. After the cellulose in the fermentation medium was completely degraded, lactose and ammonium sulfate (at a molar ratio of 10:1) were supplemented. The maximum amount of lactose added was less than $50 \mathrm{~g} / 1$. The highest cellulase activity was $5.40 \mathrm{U} / \mathrm{ml}$.

\section{Discussion}

Despite the continuous efforts of many laboratories, there are no commercially efficient cellulases that have been produced yet [40]. In this study, ARTP, a novel mutagenesis technology, was employed to find a mutant strain of $T$. reesei that could utilize lactose to efficiently produce the cellulase complex. Compared with traditional mutagenesis techniques, ARTP can cause extensive damage to DNA instantly at both room temperature and atmospheric pressure. Its superior characteristics, which include operational safety, lower costs, high mutation rate, and perfect stability of mutant strains, boost its widespread application in the mutation breeding of microorganisms [13-15].

To achieve this goal, a small amount of lactose $(3 \mathrm{~g} / \mathrm{l})$ was added to selective plates. Colonies that were surrounded with large halos that grew quickly on the selective agar plates were chosen. After 5 rounds of mutation, a hyperproducing mutant, T. reesei JNDY-13, that had a cellulase activity of $2.21 \mathrm{U} / \mathrm{ml}$, was obtained.

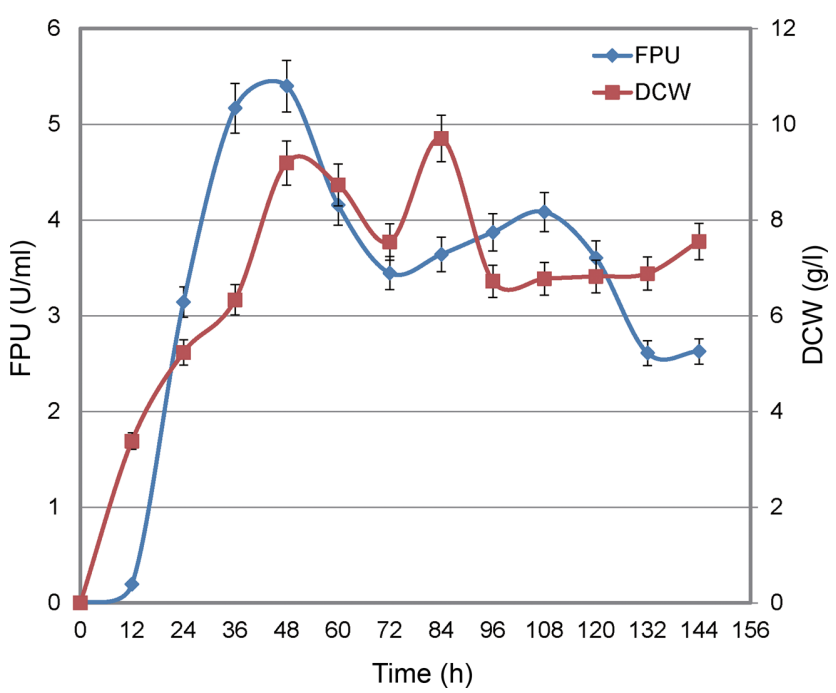

Fig. 5. Cellulase production of T. reesei JNDY-13 by fed-batch fermentation. 
In T. reesei, which is a hypercellulolytic fungus, the carbon source plays an important role in the production of cellulases. It is well-known that cellobiose, cellobiono- $\delta$ 1,5-lactone, lactose, and sophorose could enhance the production of cellulases. However, lactose is the only soluble and economically available carbon source for the production of cellulases [41-43]. Muthuvelayudham et al. revealed that the accumulation of cellulases in T. reesei QM9414 was increased when a compound of lactose and cellulose was supplemented in the fermentation medium [44]. To find a cost-effective recipe, a mixture of lactose and avicel was chosen as the carbon source, and corn steep liquor and $\left(\mathrm{NH}_{4}\right)_{2} \mathrm{SO}_{4}$ were chosen as nitrogen sources. Additionally, certain metal salts and Tween 80 were also supplemented. Then, the concentrations of the six main components were optimized by the orthogonal method using FPU as the only criterion. After batch fermentation optimization, the highest cellulase activity was $4.35 \mathrm{U} / \mathrm{ml}$. Moreover, with fed-batch fermentation, the highest cellulase activity reached $5.40 \mathrm{U} / \mathrm{ml}$.

Compared to Rut-C30, the whole-genome sequencing of the hyperproducing mutant JNDY-13 identified 752 genetic changes. Among them, the mutation in gal1, which encodes galactokinase, was of great importance because it has been reported to be closely related to the production of the cellulases complex. In fungi, lactose is hydrolyzed to galactose and glucose. Then, glucose directly enters the glycolytic pathway, and galactose enters the Leloir pathway [45]. It is subsequently converted to glucose 6-phosphate through multiple enzymatic reactions. The galactokinase of T. reesei acts as a regulatory factor in D-galactose metabolism. It is believed to be critical for both the induction of gene gal7, which belongs to the Leloir pathway, and the induction of cellulases by lactose $[33,46]$. In this study, the increased transcription of the gal1 gene might be related to increased cellulase production.

Most of the genes related to cellulases complex are regulated in a consistent way [34]. Until now, five transcription factors have been identified as regulatory factors of cellulase genes: the HAP2/3/5 complex, the positive regulators XYR1and ACE2, the repressor ACE1, and the carbon catabolite repressor CRE1 [47]. XYR1 (xylanase regulator 1) is regarded as the key expression activator of cellulase and hemicellulase genes [48]. Though CRE1 is the main transcription factor that mediates carbon catabolite repression (CCR), it is impaired in the mutant strain RUT- C30 [49]. The HAP2/3/5 complex is thought to be essential for the generation of an open chromatin structure, which is necessary for full transcriptional activation [50].
Other types of mutations that were found were changes to genes closely related to membrane transportation. The mutations of genes associated with the transmembrane transportation and the permeability of cells could have a complicated influence on the secretion of the cellulases. Moreover, several mutations that are closely related to transcription and translation levels, energy metabolism, cell growth, and reproduction were identified. These could also affect the secretion of the cellulases complex.

T. reesei is an outstanding producer of extracellular enzymes, and certain industrial strains have the capacity to produce a surprising amount (about $100 \mathrm{~g}$ of extracellular protein per liter) [51]. Recently, the FPU titers of the recombinant strain $T$. reesei zxy-2 reached $2.63 \mathrm{U} / \mathrm{ml}$ on glucose [52]. When using wheat bran as a substrate, the maximum cellulase production with T. reesei NCIM 992 was $2.63 \mathrm{U} / \mathrm{ml}$ [53]. The highest FPU of T. reesei D-78058 reached $2.60 \mathrm{U} / \mathrm{ml}$ with lactose by batch fermentation [54]. In the current study, a cellulase hyperproducing mutant T. reesei JNDY-13 had the highest cellulase activity of $5.40 \mathrm{U} / \mathrm{ml}$ during fed-batch fermentation. Whole-genome sequencing was applied to study genetic changes in JNDY13. This may lay the foundation for subsequent screening and provide novel insights into the development of a cellulase hyperproducing strain for industrial applications.

\section{Acknowledgments}

This work was supported by grants from National Natural Science Foundation of China (31500070), Natural Science Foundation of Jiangsu Province (BK20150136, BK20150151), the Fundamental Research Funds for the Central Universities (JUSRP51705A), the major science and technology projects of Zhejiang Province (2014C14SA430005), and the Open Foundation of Jiangsu Key Laboratory for Biomass-Based Energy and Enzyme Technology (BEETKA1801).

\section{Conflict of Interest}

The authors have no financial conflicts of interest to declare.

\section{References}

1. Chang MC. 2007. Harnessing energy from plant biomass. Anal. Biochem. 11: 677-684.

2. Schuster A, Bruno KS, Collett JR, Baker SE, Seiboth B, Kubicek CP, et al. 2012. A versatile toolkit for high-throughput functional genomics with Trichoderma reesei. Biotechn. Biofuels 5: 1 . 
3. Mandels M. 1985. Applications of cellulases. Biochem. Soc. Trans 13: 414-416.

4. Oksanen T, Pere J, Paavilainen L, Buchert J, Viikari L. 2000. Treatment of recycled kraft pulps with Trichoderma reesei hemicellulases and cellulases. J. Biotechnol. 78: 39-48.

5. Mach RL, Zeilinger S. 2003. Regulation of gene expression in industrial fungi: Trichoderma. Appl. Microbiol. Biotechnol. 60: 515-522.

6. Martinez D, Berka RM, Henrissat B, Saloheimo M, Arvas M, Baker SE, et al. 2008. Genome sequencing and analysis of the biomass-degrading fungus Trichoderma reesei (syn. Hypocrea jecorina). Nat. Biotechnol. 26: 553-560.

7. Christian D, Loreta GS, Sophie C, Theresa W, Mach RL, Mach-Aigner AR. 2013. Mutation of the Xylanase regulator 1 causes a glucose blind hydrolase expressing phenotype in industrially used Trichoderma strains. Biotechnol. Biofuels 6: 62 .

8. Peterson R, Nevalainen H. 2012. Trichoderma reesei RUT-C30-thirty years of strain improvement. Microbiology 158: 58-68.

9. Montenecourt BS, Eveleigh DE. 1977. Semiquantitative plate assay for determination of cellulase production by Trichoderma viride. Appl. Environ. Microbiol. 33: 178-183.

10. Montenecourt BS, Eveleigh DE. 1977. Preparation of mutants of Trichoderma reesei with enhanced cellulase production. Appl. Environ. Microbiol. 34: 777-782.

11. Montenecourt BS, Eveleigh DE. 1979. Selective screening methods for the isolation of high-yielding cellulase mutants of Trichoderma reesei. Adv. Chem. 289-301.

12. Crom SL, Schackwitz W, Pennacchio L, Magnuson JK, Culley DE, Collett JR, et al. 2009. Tracking the roots of cellulase hyperproduction by the fungus Trichoderma reesei using massively parallel DNA sequencing. Proc. Natl. Acad. Sci. USA 106: 16151-16156.

13. Laroussi M. 2005. Low temperature plasma-based sterilization: overview and state-of-the-art. Plasma Process. Polym. 2: 391-400.

14. Zhang $X$, Zhang $C$, Zhou QQ, Zhang XF, Wang LY, Chang HB, et al. 2015. Quantitative evaluation of DNA damage and mutation rate by atmospheric and room-temperature plasma (ARTP) and conventional mutagenesis. Appl. Microbiol. Biotechnol. 99: 5639-5646.

15. Fang M, Jin L, Zhang C, Tan Y, Jiang P, Ge N, et al. 2013. Rapid mutation of Spirulina platensis by a new mutagenesis system of atmospheric and room temperature plasmas (ARTP) and generation of a mutant library with diverse phenotypes. PLoS One 8: e77046.

16. Li HP, Wang ZB, Ge N, Le PS, Wu H, Lu Y, et al. 2012. Studies on the physical characteristics of the radio-frequency atmospheric-pressure glow discharge plasmas for the genome mutation of Methylosinus trichosporium. IEEE T. Plasma Sci. 40: $2853-2860$

17. Lu Y, Wang L, Ma K, Li G, Zhang C, Zhao H, et al. 2011. Characteristics of hydrogen production of an Enterobacter aerogenes mutant generated by a new atmospheric and room temperature plasma (ARTP). Biochem. Eng. J. 55: 17-22.
18. Dong XY, Xiu ZL, Li S, Hou YM, Zhang DJ, Ren CS. 2010. Dielectric barrier discharge plasma as a novel approach for improving 1,3-propanediol production in Klebsiella pneumoniae. Biotechnol. Lett. 32: 1245-1250.

19. Li G, Li H-P, Wang L-Y, Wang S, Zhao H-X, Sun W-T, et al. 2008. Genetic effects of radio-frequency, atmospheric-pressure glow discharges with helium. Appl. Phys. Lett. 92: 1460-1443.

20. Gallo BJ, Andreotti R, Roche C, Ryu D, Mandels M. 1978. Cellulase production by a new mutant strain of Trichoderma reesei MCG77. Biotechnol. Bioeng. Symp. 8.

21. Mandels M, Medeiros JE, Andreotti RE, Bissett FH. 1981. Enzymatic hydrolysis of cellulose: evaluation of cellulase culture filtrates under use conditions. Biotechnol. Bioeng. 23: 2009-2026.

22. Carder JH. 1986. Detection and quantitation of cellulase by Congo red staining of substrates in a cup-plate diffusion assay. Anal. Biochem. 153: 75-79.

23. Ahamed A, Vermette P. 2009. Effect of culture medium composition on Trichoderma reesei's morphology and cellulase production. Bioresour. Technol. 100: 5979-5987.

24. Rapp P, Grote E, Wagner F. 1981. Formation and location of 1,4-beta-glucanases and 1,4-beta-glucosidases from Penicillium janthinellum. Appl. Environ. Microbiol. 41: 857-866.

25. Kowalski ZE, Giesecke WH. 1986. A high performance liquid chromatographic method for the fluorimetric determination of lactose, galactose and glucose in normal and abnormal milk of cows. Onderstepoort J. Vet. Res. 53: 225-229.

26. IUPAC. 1987. Measurement of cellulase activities. Pure Appl. Chem. 59: 257-268.

27. Fekete E, Karaffa L, Sándor E, Seiboth B, Biró S, Szentirmai A, et al. 2002. Regulation of formation of the intracellular betagalactosidase activity of Aspergillus nidulans. Arch. Microbiol. 179: 7-14.

28. Nagy Z, Szentirmai A, Biro SKT. 2001. $\beta$-Galactosidase of Penicillium chrysogenum: production, purification, and characterization of the enzyme. Protein Expr. Purif. 21: 24.

29. Li Y, Liu C, Bai F, Zhao X. 2016. Overproduction of cellulase by Trichoderma reesei RUT C30 through batch-feeding of synthesized low-cost sugar mixture. Bioresour. Technol. 216: 503-510.

30. Ivanova C, Ramoni J, Aouam T, Frischmann A, Seiboth B, Baker SE, et al. 2017. Genome sequencing and transcriptome analysis of Trichoderma reesei QM9978 strain reveals a distal chromosome translocation to be responsible for loss of vib1 expression and loss of cellulase induction. Biotechnol. Biofuels 10: 209.

31. Kong X, He A, Zhao J, Wu H, Ma J, Wei C, et al. 2016. Efficient acetone-butanol-ethanol (ABE) production by a butanol-tolerant mutant of Clostridium beijerinckii in a fermentation-pervaporation coupled process. Biochem. Eng. J. 105: 90-96.

32. Mane SP, Modise T, Sobral BW. 2011. Analysis of highthroughput sequencing data. Methods Mol. Biol. 678: 1-11. 
33. Seiboth B, Hartl L, Pail M, Fekete E, Karaffa L, Kubicek CP. 2004. The galactokinase of Hypocrea jecorina is essential for cellulase induction by lactose but dispensable for growth on D-galactose. Mol. Microbiol. 51: 1015-1025.

34. Foreman PK, Brown D, Dankmeyer L, Dean R, Diener S, Dunncoleman NS, et al. 2003. Transcriptional regulation of biomass-degrading enzymes in the filamentous fungus Trichoderma reesei. J. Biol. Chem. 278: 31988-31997.

35. Martinez D, Berka RM, Henrissat B, Saloheimo M, Arvas M, Baker SE, et al. 2008. Corrigendum: Genome sequencing and analysis of the biomass-degrading fungus Trichoderma reesei (syn. Hypocrea jecorina). Nat. Biotechnol. 26: 553-560.

36. Li C, Yang Z, Zhang RHC, Zhang D, Chen S, Ma L. 2013. Effect of $\mathrm{pH}$ on cellulase production and morphology of Trichoderma reesei and the application in cellulosic material hydrolysis. J. Biotechnol. 168: 470-477.

37. Genichi. 1982. System of experimental design: engineering methods to optimize quality and minimize costs. American Supplier Institute.

38. Zhao Y, Cimpoia R, Liu Z, Guiot SR. 2011. Orthogonal optimization of Carboxydothermus hydrogenoformans culture medium for hydrogen production from carbon monoxide by biological water-gas shift reaction. Int. J. Hydrogen Energ. 36: 10655-10665.

39. Callow NV, Ray CS, Kelbly MA, Ju LK. 2016. Nutrient control for stationary phase cellulase production in Trichoderma reesei Rut C-30. Enzyme Microb. Technol. 82: 8-14.

40. Ahamed A, Vermette P. 2008. Culture-based strategies to enhance cellulase enzyme production from Trichoderma reesei RUT-C30 in bioreactor culture conditions. Biochem. Eng. J. 40: 399-407.

41. Bhat MK, Bhat S. 1997. Cellulose degrading enzymes and their potential industrial applications. Biotechnol. Adv. 15: 583-620.

42. Fritscher C, Messner R, Kubicek CP. 1990. Cellobiose metabolism and cellobiohydrolase I biosynthesis by Trichoderma reesei. Exp. Mycol. 14: 405-415.

43. Morikawa Y, Ohashi T, Mantani O, Okada H. 1995. Cellulase induction by lactose in Trichoderma reesei PC-3-7. Appl. Microbiol. Biotechnol. 44: 106-111.

44. Muthuvelayudham R, Deiveegan S, Viruthagiri T. 2006.
Triggering of cellulase protein production using cellulose with lactose by Trichoderma reesei. Asian J. Microbiol. Biotechnol. Environ. Sci. 8: 249-251.

45. Seiboth B, Hartl L, Pail M, Fekete E, Karaffa L, Kubicek CP. 2004. The galactokinase of Hypocrea jecorina is essential for cellulase induction by lactose but dispensable for growth on D-galactose. Mol. Microbiol. 51: 1015-1025.

46. Hartl L, Kubicek CP, Seiboth B. 2007. Induction of the gal pathway and cellulase genes involves no transcriptional inducer function of the galactokinase in Hypocrea jecorina. J. Biol. Chem. 282: 18654-18659.

47. Kubicek CP, Mikus M, Schuster A, Schmoll M, Seiboth B. 2009. Metabolic engineering strategies for the improvement of cellulase production by Hypocrea jecorina. Biotechnol. Biofuels 2: 19.

48. Stricker AR, Grosstessnerhain K, Würleitner E, Mach RL. 2006. Xyr1 (Xylanase Regulator 1) regulates both the hydrolytic enzyme system and d-xylose metabolism in Hypocrea jecorina. Eukaryot. Cell 5: 2128-2137.

49. Ilmén M, Thrane C, Penttilä M. 1996. The glucose repressor gene cre1 of Trichoderma: isolation and expression of a fulllength and a truncated mutant form. Mol. Gen. Genet. 251: 451-460.

50. Zeilinger S, Schmoll M, Pail M, Mach RL, Kubicek CP. 2003. Nucleosome transactions on the Hypocrea jecorina (Trichoderma reesei) cellulase promoter $c b h 2$ associated with cellulase induction. Mol. Genet. Genomics 270: 46-55.

51. Schmidtdannert C, Arnold FH. 1999. Directed evolution of industrial enzymes. Trends Biotechnol. 17: 135-136.

52. Zhang X, Li Y, Zhao X, Bai F. 2017. Constitutive cellulase production from glucose using the recombinant Trichoderma reesei strain overexpressing an artificial transcription activator. Bioresour. Technol. 223: 317-322.

53. Maurya DP, Singh D, Pratap D, Maurya JP. 2012. Optimization of solid state fermentation conditions for the production of cellulase by Trichoderma reesei. J. Environ. Biol. 33: 5-8.

54. Targonski Z, Pielecki J. 2010. Continuous semi-solid cultivation for the production of cellulase by Trichoderma reesei mutants using a polyurethane foam carrier and a liquid medium. Acta Biotechnol. 15: 289-296. 